\title{
Posttraumatic pericardial cyst
}

\section{Quiste pericárdico postraumático}

\section{Saldaña Dueñas ${ }^{1}$, A. Hernández Galán}

\section{RESUMEN}

Los quistes pericárdicos son lesiones poco frecuentes que se presentan como hallazgo casual en estudios radiológicos realizados por otros motivos.

La mayoría son asintomáticos ( $>50 \%)$ pero su localización y relación con estructuras vecinas determinan las manifestaciones clínicas (tos persistente, disnea, dolor torácico...)

Presentamos el caso de un paciente con dolor torácico opresivo a las dos semanas de un traumatismo torácico con una imagen sospechosa en la placa de tórax.

Palabras clave. Pericardio. Fibrilación auricular. Quiste.

\begin{abstract}
Pericardial cysts are uncommon lesions usually found incidentally upon the radiologic investigation of some other condition.

The aetiology can be both congenital and acquired (post inflammatory processes, infection or even posttraumatic). They are the most common benign tumour of the pericardium but there is still a difficulty in the differential diagnosis because even clinical or analytically are not different from some other benign or malignant lesions. Further image studies are required to complete the study of these lesions.

Even the majority are asymptomatic $(>50 \%)$, the localization and relation to adjacent structures lead the role of the clinical manifestations (persistent cough, dyspnoea, chest pain...).

We present the case of a man with oppressive chest pain after 2 weeks of thoracic traumatism with an abnormal radiological image in the chest X-ray.
\end{abstract}

Keywords. Pericardium. Auricular fibrilation. Cysts.
1. Servicio de Aparato Digestivo. Complejo Hospitalario de Navarra. Pamplona

2. Servicio de Urgencias. Complejo Hospitalario de Navarra. Pamplona

Recepción: 9 de marzo de 2015

Aceptación provisional: 31 de agosto de 2015

Aceptación definitiva: 16 de octubre de 2015

\section{Correspondencia:}

Cristina Saldaña Dueñas

Servicio de Digestivo

Complejo Hospitalario de Navarra

31008 Pamplona

E-mail: crisaldu@hotmail.com 


\section{INTRODUCTION}

The aetiology ot pericardial cysts can be both congenital and acquired (post inflammatory processes, infection or even posttraumatic). They are the most common benign tumour of the pericardium but there is still a difficulty in the differential diagnosis because even clinical or analytically are not different from some other benign or malignant lesions. Further image studies are required to complete the study of these lesions.

We present the case of a man with oppressive chest pain after 2 weeks of thoracic traumatism with an abnormal radiological image in the chest X-ray.

\section{CASE}

We present the case of a 50 year-old man with an accidental thoracic trauma with radiological findings of left costal fractures receiving anti-inflammatory treatment.

Few weeks later the patient begins with oppressive thoracic pain with dizziness different from the previous persistent costal pain. Therefore a blood test, ECG and chest X-ray are performed.

The physical examination and the laboratory findings are normal (cardiac enzymes included). The ECG shows $72 \mathrm{bpm}$ without repolarisation abnormalities.

In the X-ray a left lobulation near the hemi-diaphragm is visualized as a new finding in comparison with previous images (Fig. 1) The radiologist proposes to complete the study with a CT (Computed Tomographic scan).

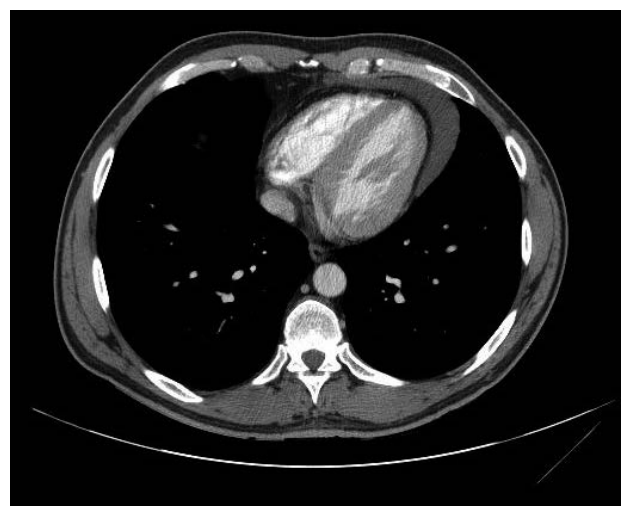

Figure 1. Chest radiograph of the patient. Posteroanterior view shows a left cardiophrenic mass (arrow) with hiperdensity near left hemi-diaphragm.
The CT describes a cyst image in the cardiophrenic angle with $8 \mathrm{~cm}$ of diameter suggesting the diagnosis or pleuro-pericardial cyst.

We derive the patient to the Neumologist Service. Respiratory function tests are performed with no abnormality. The case was presented in a multidisciplinary session and as the patient remained asymptomatic, an expectation plan is settled, with no need of a surgical approach and with cardiologic imaging follow-up.

\section{DISCUSION}

Pericardial cysts are unusually benign lesions that have a worldwide incidence of 1 per 100.000 habitants $^{4}$. The congenital encapsulated cysts arise from the pericardium in the early embryological development. Histologically these cyst are lined with a single layer of mesothelial cells that contains clear water-like fluid (so called usually as "spring water cyst") ${ }^{5,6}$. They do not frequently communicate with the pericardial cavity in the $80 \%$ of cases ${ }^{7}$. Commonly unilocular, they may appear multilocular due to constrictive fibrouse bands ${ }^{4}$.

It has been described acquired aetiology in relation of rheumatic pericarditis, bacterial infection (particularly tuberculosis) or secondary to cardiac surgery and even posttraumatic ${ }^{8}$.

Pericardial cysts have no differences in prevalence between male and female and are more frequently diagnosed in the $3^{\text {rd }}-4^{\text {th }}$ decade of life. They are usually benign and asymptomatic representing the $7 \%$ of all mediastinal masses and the first cause of a pericardial tumour ${ }^{9}$.

They are usually solitary and roundshaped masses located in the right costophrenic angle (70\%) followed by the left costophrenic angle $(10-40 \%)^{10}$. There have been described unusual localizations such as posterior mediastinum, the right or left hiliar region, the right paratracheal area, near the diaphragm or in the vicinity of the aortic $\operatorname{arch}^{4,9}$. Although the majority of patients $(>50 \%)$ remain without any symptoms, the size, localization and relation to adjacent structures define the clinical findings.

The clinical features depend on the localization of the cyst for example paratra- 
cheal and carinal cyst may lead to tracheobronquial compression, causing coughing, wheezing, dyspnoea and stridor ${ }^{11}$. In pericardial cyst a chest pain, tachycardia, persistent cough, cardiac arrhythmias (atrial fibrillation is described $^{4}$ ) dyspnoea and lower respiratory tract infection are the most common symptoms ${ }^{2}$.

If the cysts have a considerable size or a special localization they can lead to complications that include the following ${ }^{4,12}$ : sudden death, cardiac tamponade, cyst rupture, right ventricular outflow obstruction, pulmonary stenosis, erosion of the cyst into the superior vena cava and right ventricular wall, mitral valve prolapse, congestive heart faillure, atrial fibrillation, pericarditis, obstruction of the right main bronchus.

Some pericardial cysts resolve spontaneously, most likely from rupture into the pleural space. The rates of spontaneous resolution, growth or complication have not been reported ${ }^{2}$.

The pericardial cysts are usually found incidentally upon the radiologic investigation of some other condition ${ }^{1}$. The X-ray usually shows a smoothly rounded mass at the right cardiophrenic angle ${ }^{2}$ or an enlarged contour of the right heart ${ }^{12}$ but they can sometimes be confused with a coronary artery aneurysm, dextrocardia, malignancy, and even pneumonia ${ }^{2,13}$.

The differential diagnosis of mediastinal lesions includes: Morgani hernia, lipoma, angioma, neurinoma, sarcoma, lymphoma, pericardial grass, ventricular aneurism, cardiac or bronchogenic tumors, metastatic lesions, Valsalvas's senus aneurism, granulomatous lesions or abscess are some of the options ${ }^{9,10}$.

There is usually needed further investigation and the additional diagnostic methods include transthoracic echocardiuography, computer tomography and magnetic resonance imaging of the chest ${ }^{12}$.

On one hand transthoracic echocardiogram can delineate the margins and cyst character and the relation of adjacent structures. The transesophageal echocardiogram has an incremental value of the atypically located cyst. However the computed tomography and magnetic resonance offer better anatomical description of pericardial lesions. In CT pericardial cysts appear as oval, thin walled and well defined homogeneous masses. In MR they show low signal intensity on T1-weighted sequences and high signal intensity on T2-weighted sequences ${ }^{12}$.

There is no consensus of what imaging studies should be performed first. The management of a pericardial cyst depends on the distinctiveness of the cyst and the occurrence of symptoms. Some algorithms have been published, for example in the European Journal of Echocardiography, with guidelines of their management.

The general approach of pericardial cyst treatment has been question beyond the last decades. In the first case series between the 1950 and 1960 the surgical resection was the main treatment as they there were easily removed via thoracotomy. In the last years expectation plan is settled for most patients because these lesions are asymptomatic and have a benign behaviour $^{6}$. Serial transthoracic echocardiography is used to monitor asymptomatic patients and ensure a benign course in which the pericardial cyst can resolve spontaneously $^{12}$. However in many cases the exact nature of the mediastinal mass is uncertain so a surgery technique is performed.

There is no consensus in the treatment. There are those who recommend conservative treatmente as it avoids surgical morbidity and mortality, and there have been even been reports of spontaneous resolution of the cyst. Those against an expectant attitude present the risk of developing symptoms if they do not receive surgery.

In some series percutaneous fine-needle aspiration may be suggested for histologic diagnosis and possible cure of some cyst in patients with no symptoms at the diagnose $\mathrm{e}^{1,9,10}$.

Otherwise a surgical excision becomes the first option when the cyst is symptomatic: infected, possibly malignant, grows progressively or achieving giant dimensions, compressing important structures, it is atypical in location, prevention of life threatening emergencies such as cardiac 
tamponade, obstruction of right main stem bronchus and sudden death ${ }^{2,4,7}$. Excision is usually performed by video-assisted thoracic surgery ${ }^{11}$.

In conclusion, treatment is required in symptomatic patients or those with an unclear diagnosis or aggressive behaviour. In most patients a close follow-up is enough and is performed by serial transthoracic echocardiography ${ }^{3}$.

\section{BIBLIOGRAPHY}

1. Esme H, Eren S, Sezer M, Solak O. Primary mediastinal cysts. Tex Heart Inst J 2011; 38: 371374.

2. Elamin WF, Hannan K. Pericardial cyst: an unusual cause of pneumonia. Cases J 2008; 1: 26.

3. Ozturk E, Aparci M, Haholu A, Sonmez G, Mutlu $\mathrm{H}$, BaseKIM CC et al. Giant dumbbell-shaped pericardial cyst. Tex Heart Inst J 2007; 34: 386-387.

4. Omeroglu SN, Omeroglu A, Ardal H, Erkilinc A, BAL E, IPEK G et al. Epicardial mesothelial cyst. Tex Heart Inst J 2004; 31: 313-315.

5. Patel J, Park C, Michaels J, Rosen S, Kort S. Pericardial cyst: case reports and a literature review. Echocardiography 2004; 21: 269-272.
6. Schweigert M, Dubecz A, Beron M, Ofner D, Stein HJ. The tale of spring water cysts. Tex Heart Inst J 2012; 39: 330-334.

7. Benito-Conejero SL, Camacho-Vázquez C, Maroto-Monserrat F. Quiste pericárdico post-traumático de localización atípica. An Med Interna (Madrid) 2005; 22: 594-596.

8. Maisch B, Seferović PM, Ristić AD, Erbel R, RienMÜLLER R, ADLER Y et al. Guidelines on the diagnosis and management of pericardial diseases executive summary; The Task force on the diagnosis and management of pericardial diseases of the European society of cardiology. Eur Heart J 2004; 25: 1-28.

9. Gervilla J, Soler J, Melé J, Domingo P, Mayolas E, Oriol Z et al. Quiste pericárdico. Semergen 2010; 36: 174-176.

10. Zambudio AR, Lanzas JT, Calvo MJ, Fernández PJ, PARICIO PP. Non-neoplastic mediastinal cysts. Eur J Cardiothorac Surg 2002; 22: 712-716.

11. NaJib MQ, Chaliki HP, Raizada A, Ganji JL, Panse PM, CLICK RL. Symptomatic pericardial cyst: a case series. Eur J Echocardiogr 2011;12: E43.

12. KEI J. Image diagnosis. Pericardial cyst. Perm J 2013; 17: E149.

13. Portillo-Carroz K, Miguel-Campos E, Montoliú TARRAMERA R. Quiste pleuropericárdico: un buen final para un mal inicio. Rev Esp Cardiol 2006; 59: 1079-1083. 